\title{
Shredding of polyethylene terephthalate waste
}

\author{
Natalya Fomina ${ }^{1 *}$, Vadim Khozin ${ }^{2}$, Aleksandr Strakhov ${ }^{1}$, and Artur Ismagilov ${ }^{1}$ \\ ${ }^{1}$ Yuri Gagarin State Technical University of Saratov, Department Building Materials and \\ Technologies, 410054 Polytechnic St., 77, Saratov, Russia \\ ${ }^{2}$ Kazan State University of Architecture and Engineering, Department Technology of building \\ materials, products and constructions, 420043 Zelenaya St., 1, Kazan, Russia
}

\begin{abstract}
Methods of recycling polyethylene terephthalate waste are analyzed. Thermoplastic waste has great potential for mechanical recycling. Lack of information on the quality of recycled products and their applicability for specific purposes hinders their use. Shredding is a main process in mechanical recycling. Due to the viscoelastic properties, the cost of grinding polymer waste is several times higher than for most brittle mineral materials. Cutting and impact equipment is often used to shred plastic waste. To obtain micron-sized polymer particles, the technologies of cryogenic grinding and wet grinding in solvents are used, which is followed by high operating costs. The purpose of this work was to develop an economical method for producing fine powders from polyethylene terephthalate waste. The specific surface of the powders has been investigated. To investigate the destruction, differential thermal analysis and infrared spectroscopy were used. The technology of secondary mechanical recycling is proposed: crushing, melting of waste, natural or water cooling of the melt, grinding on equipment typical for brittle materials. A dispersed product with a proportion of micronized fraction of about $50 \%$ was obtained for use as filler in composites. The resulting product is more degraded in comparison with the feedstock. Therefore, its use as binders is advisable in applications where a decrease in initial properties is permissible, in products with a long lifecycle, for example, in the production of building materials. The use of waste thermoplastic in applications other than the original one does not always reduce the value of the technology.
\end{abstract}

\section{Introduction}

Disposal of plastic waste in recent decades has become a serious environmental problem throughout the world [1-3, etc.]. In accordance with the basic principles of the circular economy, the regulations for the implementation of which began to be developed in 2017 [4], recycling has become the most desirable strategy for the disposal of plastic waste. The terminology for recycling plastic waste is still being formed and is constantly changing. The classification of disposal methods (in accordance with Russian (GOST R 54533-2011) and European [5-7] standards) in relation to polymer composites are presented in table. 1.

* Corresponding author: fominanani@yandex.ru 
The practical implementation of processing is influenced by two main economic factors: the price of the processed polymer in comparison with the virgin one; investment in recycling versus alternative disposal methods.

For thermoplastic waste, mechanical processing is more economically efficient, compared to energy recovery, even taking into account the costs of grinding, washing, sorting and other types of preparation $[6,7]$. The environmental benefits are also evident. Lack of information on the availability and volumes of recycled plastic, its quality and applicability for specific purposes hinders the use of mechanical recycling products $[6,8]$.

Table 1. Methods for processing waste polymers and polymer composites.

\begin{tabular}{|c|c|c|c|}
\hline Processing methods & Technology features & $\begin{array}{c}\text { Completed process } \\
\text { product }\end{array}$ & $\begin{array}{c}\text { Complexities, } \\
\text { disadvantages of } \\
\text { technology }\end{array}$ \\
\hline $\begin{array}{l}\text { primary mechanical } \\
\text { recycling (return to } \\
\text { production, } \\
\text { closed loop } \\
\text { recirculation) }\end{array}$ & $\begin{array}{l}\text { the possibility of } \\
\text { multiple recycling; } \\
\text { no separation of } \\
\text { matrix and filler }\end{array}$ & $\begin{array}{l}\text { granulate; } \\
\text { intermediate } \\
\text { product }\end{array}$ & $\begin{array}{l}\text { degradation of } \\
\text { matrix properties at } \\
\text { each stage of } \\
\text { recycling }\end{array}$ \\
\hline $\begin{array}{l}\text { secondary mechanical } \\
\text { recycling, "lowering" } \\
\text { (grinding, mixing with } \\
\text { other components) }\end{array}$ & $\begin{array}{l}\text { the possibility of } \\
\text { multiple recycling; } \\
\text { partial separation of } \\
\text { matrix and filler is } \\
\text { possible }\end{array}$ & $\begin{array}{l}\text { crushed particles; } \\
\text { possible particles } \\
\text { with most of the } \\
\text { filler or with most } \\
\text { of the matrix }\end{array}$ & $\begin{array}{l}\text { degradation of } \\
\text { matrix properties } \\
\text { due to mechanical } \\
\text { destruction; } \\
\text { fiber breaks }\end{array}$ \\
\hline $\begin{array}{l}\text { tertiary chemical or } \\
\text { thermochemical } \\
\text { (extraction of chemical } \\
\text { components), or } \\
\text { biological (organic) } \\
\text { recycling }\end{array}$ & $\begin{array}{l}\text { dissolution or } \\
\text { decomposition of the } \\
\text { matrix; }\end{array}$ & $\begin{array}{l}\text { filler particles; } \\
\text { low molecular } \\
\text { weight substances; } \\
\text { biogas; } \\
\text { compost }\end{array}$ & $\begin{array}{l}\text { complicated } \\
\text { equipment; high } \\
\text { technology cost; } \\
\text { emissions of toxic } \\
\text { substances; } \\
\text { technology } \\
\text { selectivity }\end{array}$ \\
\hline energy recovery & matrix decomposition & $\begin{array}{c}\text { filler particles; } \\
\text { recovered energy } \\
\text { (thermal or electric) }\end{array}$ & $\begin{array}{l}\text { irrecoverable loss of } \\
\text { matrix polymer; } \\
\text { emissions of toxic } \\
\text { substances }\end{array}$ \\
\hline
\end{tabular}

The main technological process of mechanical recycling - grinding, in relation to polymer waste, can pursue the following goals:

- reduce the volume, increase the density of waste;

- increase homogeneity, separate impurities;

- to receive a product suitable for further transportation, dosing, transfer to the production cycle;

- to obtain particles with a size corresponding to the design of the future product or processing equipment;

- to increase the specific surface of the particles, thus, to obtain a surface developed for interfacial interaction.

Polymeric materials inherently have specific mechanical properties - high tensile and tear strength, impact strength, elongation at break. Accordingly, the technologies for crushing polymer waste are also specific. The energy spent on grinding viscoelastic materials is one to two orders of magnitude higher than for most brittle mineral materials [9-11]. In theory, particles are destroyed if the elastic energy stored in them exceeds the 
critical energy required for crack propagation. In polymers under load, energy can be accumulated both elastically and dissipated due to plastic deformation. Considering the process at the micro level, due to the weak intermolecular interaction, weakly bound polymer chains will stretch, smooth the opening of cracks, and only a significant increase in stress energy will lead to destruction [10].

For crushing plastic waste, cutting and impact equipment is usually used - shredders, impact crushers [9-10]. Particle size at the exit from industrial (for example, https://atlasmash.ru/) shredders is about 20-200 mm; from crushers - 5-20 mm. For some applications, this is sufficient: for the production of secondary granules from thermoplastic waste; for the production of aggregates into asphalt concrete, cement concrete from any polymer and composite waste. If a powdery state of the particles is required, fine grinding micronization is required [9]. For these purposes, impact disc micronizer mills are used (the particle size at the outlet does not exceed $1 \mathrm{~mm}$ ); dry ball mills [10]; jet mills, where grinding is achieved due to the collision of particles in vortex flows; aggregates based on solid-phase shear extrusion technology (particle size at the outlet 0.02-2 mm) [9, 10]; knife mills [12] (particle size at the outlet up to $0.4 \mathrm{~mm}$ ); mills based on mechanochemical processes, for example, described in [13], in which a pair of three-dimensional shears creates a very strong shear force, resulting in fine polymer powders.

Even more finely dispersed particles can be obtained by cryogenic grinding, because at ambient temperature, milling of viscoelastic and plastic materials is energy intensive, expensive or even impossible [11]. In the scientific literature, much attention is paid to cryogenic grinding of polymer wastes $[11,14]$ to obtain ultrafine powders from them. Indeed, the fracture properties of brittle materials depend little on temperature and impact speed. In polymers, with decreasing temperature, the elastic modulus increases, the fracture toughness decreases, the material becomes more brittle, and the grinding efficiency increases, especially at high impact speeds [10]. For cooling, liquid nitrogen $\left(-196^{\circ} \mathrm{C}\right)$ or solid carbon dioxide $\left(-78^{\circ} \mathrm{C}\right)$ is used $[10,11]$, which is accompanied by high operating costs.

In [14], the advantages of cryogenic grinding for polymer-containing waste of complex composition are shown. So, if the waste contains metal components (for example, medical blisters with foil layers or lead-containing plastic elements of used batteries), grinding at normal temperatures leads to heating of the mass, melting of the polymer and a sharp decrease in grinding efficiency. Cryogenic grinding, although more expensive, is a necessary procedure for such waste [14]. For cryogenic grinding, it is important that the finer the particles, the faster they adapt to the ambient temperature. Therefore, it is necessary to cool both the particles and the mill. According to [11], for grinding $1 \mathrm{~kg}$ of viscoelastic material, from 0.6 to $6 \mathrm{~kg}$ of liquid nitrogen is required, which is more than $40 \%$ of the grinding costs. Thus, cryogenic grinding is justified when ultrafine powders are needed or when the waste is multicomponent, difficult to separate, and when an increase in temperature during grinding is highly undesirable.

Grinding processes at moderately low temperatures are also being investigated. In [10], wet grinding of polystyrene and polyetheretherketone in a bead mill, in a liquid medium of ethanol and hexane, respectively, at moderately low temperatures (down to -80 $\left.{ }^{\circ} \mathrm{C}\right)$ was studied. Particles less than 5 microns in size with a narrow granulometry were obtained. In this case, obviously, an important role is played by the properties of the solvent - the grinding medium.

When obtaining fine powders from polymer wastes for their subsequent use in the same applications as the starting material (for example, "bottle-in-bottle" technology), it is obviously necessary to preserve the quality of the polymer in the recycling process and prevent destruction. But if the goal is to obtain a filler from the polymer waste, then the degree of polymer destruction is of secondary importance. Here, a more important role is 
played by density, degree of dispersion, granulometry of powders, degree of surface roughness - to increase interfacial adhesion in composites. The economic component is also very important for the processing to be realistic and commercially attractive.

In this work, the purpose was to investigate methods for producing fine powders from polyethylene terephthalate waste (widespread, well-collecting and sorting thermoplastic waste) using crushing and grinding equipment typical for brittle mineral materials.

\section{Materials and Methods}

For research, we took shredded waste of polyethylene terephthalate (particles with a size of 10-30 mm) obtained from a mixture of transparent and colored bottles for carbonated drinks. A virgin polymer (film) was also used for comparison. The following designations have been introduced for research objects:

- $\quad$ PET - virgin polymer;

- $\quad$ rPET - primary recycling product;

- $\quad$ rPET-S - secondary recycling product obtained by slow natural cooling of the melt from the primary recycling product;

- $\quad$ r-PET-R - the same, but with rapid water cooling of the melt.

The specific surface of the powders was measured by the gas permeability method. Sieve analysis was also used. Differential thermal analysis (DTA) and thermogravimetry (TG) were used to study thermal effects and temperature transitions. Infrared (IR) spectroscopy was used to identify functional groups in the polymer. The relative integral absorption intensity of the carbonyl and hydroxyl groups in the IR spectra was calculated as the ratio of the absorption peak area of the corresponding group to the absorption peak area of the valence conjugated $\mathrm{C}=\mathrm{C}$ bonds of the aromatic ring in the region of $1505 \mathrm{~cm}^{-1}$.

\section{Results and Discussion}

It is known $[9,15-16]$ that each subsequent melting of a thermoplastic is accompanied by destructive processes, a decrease in molecular weight and embrittlement. This was a prerequisite for increasing the efficiency of grinding polymer waste on standard grinding equipment that is used for brittle mineral materials. Shredded waste rPET was melted at $260-280{ }^{\circ} \mathrm{C}$. At this temperature, the process proceeds quickly, the melt becomes brown. It is known that the regularity of the molecular structure of PET determines its tendency to crystallization [16], slow cooling of the melt promotes this process, and the degree of crystallinity of the material is likely to affect grindability. Therefore, the melt was cooled in two ways:

1. naturally at room temperature (in Fig. 1, the melt is poured into a form). Upon slow cooling, the color of the melt turns into an opaque gray (seen in Fig. 1, along the perimeter of the form), which indirectly indicates some crystallization of the polymer (sample - rPET-S);

2. rapid water cooling to prevent crystallization. In water with a temperature of $18-22^{\circ} \mathrm{C}$, the solidified mass acquired a transparent amber color (sample - rPET-R). 


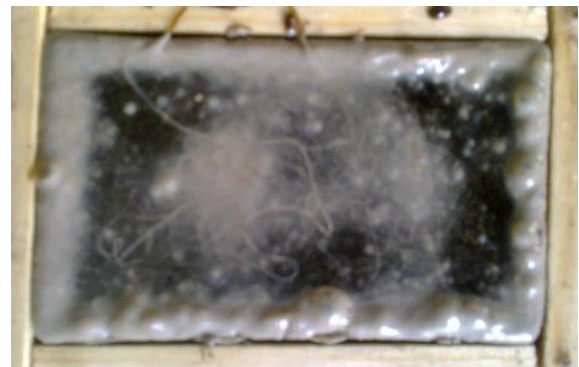

rPET-S

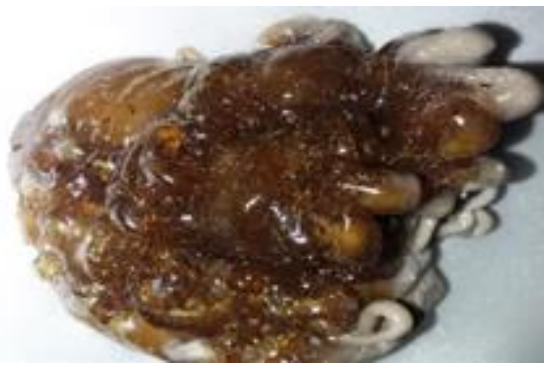

rPET-R

Fig. 1. Samples in the process of cooling the melt.

The solidified and cooled rPET-S samples were divided into two parts. The first part was crushed in a one-stage way in a ball mill, the second part - in a two-stage way: first in a rotary crusher, and then in a ball mill. The rPET-R samples were milled in a two-stage method only. The grinding process proceeded similarly to the grinding of brittle mineral materials. In all cases, the products of grinding during sieving completely passed through a sieve of $2.5 \mathrm{~mm}$. From the dispersion characteristics presented in table. 2, it follows that even a one-stage grinding gives a sufficiently high amount of micronized fraction (fraction less than $0.16 \mathrm{~mm}$ ). Two-stage grinding allows to obtain a finer product, as indicated by higher specific surface area. No significant differences in grindability were found for rPET samples with different degrees of crystallinity.

Table 2. Grinding product characteristics.

\begin{tabular}{|c|c|c|c|}
\hline \multirow{2}{*}{ Sample } & Grinding method & $\begin{array}{c}\text { Specific surface, } \\
\mathbf{c m}^{\mathbf{2}} / \mathbf{g}\end{array}$ & $\begin{array}{c}\text { The amount of micronized fraction } \\
\text { (less than } \mathbf{0 . 1 6} \mathbf{~ m m}) \mathbf{\%}\end{array}$ \\
\hline \multirow{2}{*}{ rPET-S } & one-stage & 446 & 48 \\
\cline { 2 - 4 } & two-stage & 735 & 52 \\
\hline rPET-R & two-stage & 769 & 52 \\
\hline
\end{tabular}

Thus, re-melting of rPET improves its grindability. Due to the high dispersion, the resulting polymer powders can be used as fillers for composite materials, primarily, based on thermodynamic compatibility, in polymer composites, both based on thermosetting and thermoplastic matrices.

If we consider the obtained polymer powders for other applications, where the binding properties of the polymer can be realized, it is necessary to understand the degree of its degradation. Embrittlement, as well as visually observed changes in color and transparency in the polymer upon re-melting, all indicate destructive processes. The reasons can be both thermal and mechanical effects, and impurities, and additives present in the waste $[9,16-$ 19]. For rPET municipal waste, it may contain contaminants in the form of adhesive residues and labels containing, inter alia, polyvinyl chloride or ethylene vinyl acetate. Even very small amounts of them during secondary recycling intensify the destruction of PET, because in the temperature range of its melting, polyvinyl chloride intensively decomposes with the release of gaseous hydrogen chloride, ethylene vinyl acetate - with the release of acetic acid, which in turn catalyze the hydrolysis of the ester bonds of PET [9]. It is also well known that a very low residual moisture (more than $0.02 \%$ ) of PET leads to hydrolysis under thermal effects [9, 16-17, 20]. 
To study the degree of destruction from the studied samples (rPET-S, rPET-R), and, for comparison, from PET and rPET, IR spectra were obtained (Table 3). In the region of intramolecular interactions (1800-1500 $\left.\mathrm{cm}^{-1}\right)$, an intense absorption band of stretching vibrations of the carbonyl group is indicative. The intensity of this band is minimal for the original PET, and increases in all samples of recycled products. Here, the absorption spectra of carbonyl groups of various origins can be superimposed: $\mathrm{C}=\mathrm{O}$ of terminal carboxyl groups and $\mathrm{C}=\mathrm{O}$ of the ester bond in polymer macromolecules. It is known [21] that this band shifts to higher frequencies when hydroxyl is added to the carbon atom of the carbonyl group. This is exactly what is observed in all recycled products, which indicates the appearance of a certain amount of terminal carboxyl groups. In the range of absorption of the hydroxyl group in the region of $3650-3000 \mathrm{~cm}^{-1}$, the relative integral intensity is minimal in the sample of the initial PET, in the products of recycling the intensity increases. At the same time, no significant difference in the IR spectra of the products of primary and secondary recycling was found.

Additionally, we examined the samples using DTA and TG (Table 3). The melting of the recycled products begins somewhat earlier than the melting of the initial polymer, and rPET-R has the lowest melting point $\left(210^{\circ} \mathrm{C}\right)$. Weight loss is not observed up to $330{ }^{\circ} \mathrm{C}$ for all the samples studied, and this is consistent with [20] for various PET wastes. With an increase in temperature, thermal oxidative destruction begins, accompanied by the release of gaseous products, the main of which are terephthalic acid, acetaldehyde, and carbon monoxide [16]. The process proceeds with intense heat release and mass losses up to temperatures of $430-450{ }^{\circ} \mathrm{C}$. Moreover, the weight loss for the initial polymer and the primary recycling product are close (79 and $80 \%$, respectively), and exceed the weight loss for the secondary recycling products $(73-75 \%)$. This indicates their prehistory - about 6-7 $\%$ of the mass, these samples lost in the process of re-melting.

Table 3. Analysis of DTA, TG and IR spectra of samples.

\begin{tabular}{|c|c|c|c|c|}
\hline & PET & rPET & rPET-S & rPET-R \\
\hline \multicolumn{5}{|c|}{ Analysis of derivatograms and thermograms } \\
\hline Melting temperature range, ${ }^{\circ} \mathrm{C}$ & $235-255$ & $225-250$ & $225-240$ & $210-240$ \\
\hline Weight loss at $330{ }^{\circ} \mathrm{C}, \%$ & \multicolumn{4}{|c|}{0} \\
\hline $\begin{array}{l}\text { Temperature range of intense thermo-oxidative } \\
\text { destruction, }{ }^{\circ} \mathrm{C}\end{array}$ & $335-430$ & $340-450$ & $335-450$ & $320-440$ \\
\hline Weight loss at $450{ }^{\circ} \mathrm{C}, \%$ & 79 & 80 & 73 & 75 \\
\hline $\begin{array}{l}\text { Temperature range of combustion products of } \\
\text { destruction, }{ }^{\circ} \mathrm{C}\end{array}$ & $430-615$ & $450-620$ & $450-670$ & $440-620$ \\
\hline Weight loss at $700{ }^{\circ} \mathrm{C}, \%$ & \multicolumn{4}{|c|}{94} \\
\hline Coke residue, $\%$ & \multicolumn{4}{|c|}{6} \\
\hline \multicolumn{5}{|c|}{ Analysis of IR spectra } \\
\hline $\begin{array}{l}\text { Position of the absorption band of the carbonyl } \\
\text { group, } \mathrm{cm}^{-1} \text {; }\end{array}$ & 1719 & 1725 & 1723 & 1722 \\
\hline Relative integral absorption intensity & 21 & 38 & 35 & 37 \\
\hline $\begin{array}{l}\text { Position of the absorption band of the hydroxyl } \\
\text { group, } \mathrm{cm}^{-1} \text {; }\end{array}$ & 3430 & 3425 & 3427 & 34272 \\
\hline Relative integral absorption intensity & 1 & 8 & 2 & 2 \\
\hline
\end{tabular}




\section{Conclusions}

Thus, we offer a quite simple and economical technology for secondary mechanical recycling of PET waste. The process includes crushing waste, melting (in melting and mixing equipment), natural or rapid water cooling of the melt, followed by grinding. For grinding, the equipment is used, typical for brittle mineral materials of low hardness, in the same modes with similar energy consumption. The result is a dispersed product up to 2.5 $\mathrm{mm}$ in size, with a micronized fraction (finer than $0.16 \mathrm{~mm}$ ) about $50 \%$. This product can be used as a filler in composites based on various, primarily polymer matrices.

The resulting product of secondary recycling of PET waste is more degraded in comparison with the initial raw material. Therefore, the use of PET wastes, especially contaminated ones, as binders is advisable in applications where a decrease in the initial deformation and strength properties of the polymer, its color and transparency is acceptable. The melting point lowered relative to the initial PET (by $10-25^{\circ} \mathrm{C}$ ) allows to reduce the cost of technological processing into products.

Destructive processes at each stage of recycling of polymer waste determine the feasibility of recycling waste into products with a long lifecycle, and the most diverse industry for this is the production of building materials, where there is a need for durable products with high decorative effect. Using the binding properties of thermoplastic waste, on their basis, it is promising to manufacture such construction and finishing products as paving slabs [22], facing, tactile tiles, curb stones, parking stops, sewer manhole covers, elements of garden and park design, including complex and etc.

The volume of polymer production is increasing every year, especially for thermoplastics, which are replacing thermosets and other non-polymer materials in many applications. Therefore, recycling thermoplastic waste and finding effective applications for their use is an important task. Moreover, the transition of thermoplastic waste to another application, different from the original one, does not necessarily reduce the value of the technology. As rightly noted in [23], the circular economy is not a cascading transition of waste into less and less valuable areas of application, but a reasonable and most expedient application. The high cost of processing today will in the future be offset by legislation that sharply restricts or prohibits the disposal and incineration of polymer and polymercontaining waste.

\section{References}

1. R. Geyer, J. Jambeck, K.L. Law, Science Advances, 3, 7 (2017)

2. Directive 2008/98/EC on waste, in: European Commission (2008)

3. Sustainable Plastics Strategy. Edition 2 (December 2020)

4. BS 8001:2017: Framework for implementing the principles of the circular economy in organizations (2017)

5. Plastics and the environment. Ed. A. Andrady (Hoboken, NJ: Wiley Interscience, 2003)

6. J. Hopewell, R. Dvorak, E. Kosior, Phil. Trans. R. Soc. B (2009)

7. J. Marisa, S. Bourdon, J.-M. Brossard, L. Cauret, L. Fontaine, V. Montembault, Polym. Degrad. Stab. 147 (2018)

8. Rynok upakovki. Sostoyanie, trendy i innovacii. Polimernye materialy, 11, 43-50 (2020)

9. J. Scheirs, Polymer Recycling: Scince, Technology and Applications (JohnWiley \&Sons, 2012)

10. J. Schmidt, M. Plata, S. Tröger, W. Peukert, Powder Technol, 228, 84-90 (2012) 
11. M. Wilczek, J. Bertling, D. Hintemann. Int. J. Miner. Process, 74S, 425-434 (2004)

12. E.G. Ashton, W. Kindlein Jr., R. Demori, L.H.A. Candido, R. Mauler, Journal of Cleaner Production, 116, 268-278 (2016)

13. S. Yang, F. Zhong, M. Wang, S. Bai, Qi Wang, Journal of Industrial and Engineering Chemistry, 57, 143-143 (2018)

14. V. Gente, F.La Marca, F. Lucci, P. Massacci, E. Pani, Waste Manage, 24, 663-672 (2004)

15. N.N. Fomina, M.M. Polyanskij, V.G. Fomin, Vliyanie temperaturnyh vozdejstvij na polietilentereftalat $v$ processe pererabotki polimernyh othodov $v$ stroitel'nye izdeliya, in Proceedings of the 10 All-Russian Conference "Neobratimye processy v prirode i tekhnike", Moscow, Bauman Moscow State Technical University, 29-31 January 2019, 1, 214-216 (2019)

16. F. La Mantiya, Vtorichnaya pererabotka plastmass. Ed. G.E. Zaikov (St. Petersburg: Professiya, 2006)

17. V. Goodship, 11 - Recycling issues in polymer matrix composites. Ed.: P. Robinson, E. Greenhalgh, S. Pinho, In Woodhead Publishing Series in Composites Science and Engineering, Failure Mechanisms in Polymer Matrix Composites, 337-367 (Woodhead Publishing, 2012)

18. F. Maisel, P. Chancerel, G. Dimitrova, J. Emmerich, N. F. Nissen, M. SchneiderRamelow. Resources, Conservation \& Recycling, 154, 104619 (2020)

19. Management, recycling and reuse of waste composites. Ed. V. Goodship (Woodhead Publishing, 2010)

20. M.K. Eriksen, J.D. Christiansen, A.E. Daugaard, T.F. Astrup, Waste Manage, 96, 7585 (2019)

21. I. Dekhant. Infrakrasnaya spektroskopiya polimerov, 472 (Moscow, Himiya, 1976)

22. N.N. Fomina, Yu.G. Ivashchenko, M.M. Polyanskij. Patent RU 2623754 (2017, bul. 19)

23. K. Ragaert, L. Delva, K.V. Geem, Waste Manage, 69, 24-58 (2017) 